\title{
Estado y Constituciones en Paraguay: un análisis de las Cartas Magnas de 1844, 1870 y 1940
}

Magdalena López*

Fecha de Recepción: 1 de agosto de 2021

Fecha de Aceptación: 24 de septiembre de 2021

DOI: https://doi.org/10.46553/RGES.57.2021.p.207-232

\section{Resumen}

Este trabajo propone un estudio comparativo de textos constitucionales de tres momentos diferentes pero consecutivos de la historia política de Paraguay. Indagamos las Constituciones de 1844, 1870 y 1940, siendo la primera la pionera, la segunda el resultado de un proceso de ocupación por haber sido Paraguay derrotado en la Guerra contra la Triple Alianza, y la última una herramienta jurídica que permitió la perduración de gobiernos autoritarios y dictatoriales. Esta exégesis constitucional se llevó adelante a partir de cuatros ejes específicos que nos permitió identificar las formas que el Estado presentaba en esas Constituciones, tanto en los efectos que querían generarse al ponerlas en vigencia, como en el marco de situación que expresan al sancionarse. Estos ejes son: la organización política del poder, los sujetos sociales reconocidos y los derechos asignados, la relación con la Iglesia, y el diseño de una matriz productiva, económica o de propiedad privada.

Palabras clave: Paraguay; Constitución; Poder; Sociedad; Iglesia y Economía

\begin{abstract}
This work proposes a comparative study of constitutional texts from three different but consecutive moments in the political history of Paraguay. We inquire into the Constitutions of 1844, 1870 and 1940, being the first the pioneer, the second the result of an occupation process because Paraguay was defeated in the War against the Triple Alliance, and the last one a legal tool that helped to the permanence of authoritarian and dictatorial governments. This constitutional exegesis was carried out from four specific axes that will seek to identify the forms that the State presented in those Constitutions, both in the effects they wanted to generate when they were put into effect, and in the situation framework that it expresses when it is sanctioned. These axes are: the political organization of power, recognized social subjects and assigned rights, the relationship with the Church, and the design of a productive, economic or private property matrix.
\end{abstract}

Keywords: Paraguay. Constitution. Power, Society, Church and Economy

\section{Introducción}

CONICET / Universidad de Buenos Aires. Instituto de Investigaciones Gino Germani Grupo de Estudios Sociales sobre Paraguay, Instituto de Estudios de América Latina y el Caribe. magui@sociales.uba.ar 
Los estudios de las Constituciones han abonado un campo de desarrollo prolífero dentro de las ciencias políticas, históricas y jurídicas. Sin embargo, muchas veces quedan limitados a una enumeración descriptiva de artículos, sin analizar en profundidad la visión de Estado, de ciudadanía y de sistema político que, al mismo tiempo, estas Constituciones presuponen, promueven y retroalimentan.

Respecto a los abordajes del Estado en América Latina, Lechner marca que, al evadir la definición del concepto, estos trabajos "hacen del estado una categoría residual para designar una colorida mezcla de gobierno, estructura de poder, dominación de clase, políticas públicas, marco legal, dirección ideológica, etc.". ${ }^{1}$ Al mismo tiempo, advierte sobre el problema de partir de una definición tan estricta, que no permita interpretar adecuadamente la realidad regional y la especificidad de cada unidad territorial.

En Latinoamérica, el Estado hereda formas de la colonia que combina y articula con mecanismos y estructuras de poder novedosas o adaptadas a la realidad local. Además, el nacimiento de las formas estatales modernas se asoció, en palabras de Oszlak, ${ }^{2}$ a ciertos atributos de estatidad, centralmente a la capacidad de externalizar el poder, la de institucionalizar la autoridad, la de diferenciar el control y la de internalizar una identidad colectiva. Agregamos, también, la relación entre el Estado y ciertas matrices económicas productivas.

Siguiendo estas premisas, este trabajo se propone analizar la concepción de Estado que subyace a las Constituciones nacionales de tres momentos históricos diferentes en Paraguay, a partir de 4 ejes que aportarán originalidad al abordaje, pues permitirán avizorar las transformaciones sociopolíticas: la construcción del poder institucionalizado, de la ciudadanía con derechos, de la coexistencia con la Iglesia y de la propiedad privada y productiva, como se detallarán en el siguiente apartado.

Nos proponemos analizar críticamente tres Cartas Magnas, es decir, tres textos normativos centrales que proveyeron, o buscaron instaurar, un orden institucional y político en Paraguay. La originalidad de este aporte es incorporar constituciones de tres momentos diferentes pero muy relevantes para la historia del país: 1) la Ley de Administración Pública de 1844, proveniente de la temprana independencia, en un período previo a la Guerra contra la Triple Alianza que marcó los designios políticos, sociales, económicos y culturales del país;

\footnotetext{
${ }^{1}$ Lechner, Norbert. "Presentación". En Estado y política en América Latina. Editado por Norbert Lechner. (México: Siglo XXI Editores, 2000). p. 7.

${ }^{2}$ Oszlak, Oscar. "Formación histórica del Estado en América Latina: elementos teórico-metodológicos para su estudio", en Lecturas sobre el Estado y las políticas públicas: Retomando el debate de ayer para fortalecer el actual. Compilado por la Jefatura de Gabinete de Ministros. (Buenos Aires: Jefatura de Gabinete de Ministros, 2011).
} 
2) La Constitución de 1870, posbélica, considerada la primera que acoge los preceptos del liberalismo canónico; y 3) la Constitución de 1940 de José Félix Estigarribia, caracterizada por erosionar los principios democráticos y fortalecer una visión centralista y autoritaria del poder; estableciendo las bases jurídicas de dictadores posteriores (sobresaliendo la figura de Alfredo Stroessner, quien encabezó una dictadura de tres décadas y media entre 1954 y 1989, gobernando hasta 1967 con la Carta de Estigarribia).

La indagación crítica de estos documentos nos permitirá revisar la historia paraguaya, estudiando qué representaciones de Estado eran hegemónicas en estas Cartas Magnas y qué elementos allí disponibles nos permiten visualizar cuales eran los resultados que se esperaban de la aplicación de estos nuevos marcos jurídicos.

Hacemos aquí una salvedad: la prescripción de formas estatales, políticas y gubernamentales en el cuerpo de una norma escrita, no las hace entrar en rigor ni tampoco da cuenta del impacto o la resistencia social que generan.

\section{Algunos elementos conceptuales y metodológicos}

El Estado como objeto de estudio, a partir del análisis constitucional como herramienta y de los abordajes interpretativos cualitativos como metodología, nos obliga a determinar ejes o referencias que permitan aprehender y categorizar el gran concepto que debemos definir, describir y comprender. ¿Qué Estado se buscaba construir, fortalecer o imponer a través de las Constituciones? ¿Cómo puede analizarse las diferentes aristas de estos Estados? ¿Qué elementos se incorporan para entender las tensiones entre el Estado existente y el que quiere imponerse?

En una interesante compilación, Fradkin, ${ }^{3}$ junto a otros autores, recorta al Estado a partir de la justicia, el poder institucional, la relación con la Iglesia, la construcción de las figuras delictivas y la producción normativa (imperio de la ley, control de la población, construcción del poder). ${ }^{4}$ También existen sólidos antecedentes que han indagado en la ciudadanía y en la nación para dar cuenta del proceso estatal y su modernización (como los trabajos de Sábato $^{5}$ y de Guerra ${ }^{6}$ ).

\footnotetext{
${ }^{3}$ Fradkin, Raúl O. (Comp.) El poder y la vara. Estudios sobre la justicia y la construcción del Estado en el Buenos Aires rural. (Buenos Aires: Prometeo, 2007).

${ }^{4}$ Una tarea similar realizaron Bohoslavsky y Godoy Orellana (2010) para describir la construcción estatal argentina.

${ }^{5}$ Sábato, Hilda (Coord.) Ciudadanía política y formación de las naciones: Perspectivas históricas. (México: FCE, 1999).
} 
Refiriéndonos al caso paraguayo, Rivarola $^{7}$ hizo un aporte fundamental para comprender las formas en las que el Estado del Siglo XIX logró intervenir la sociedad para obtener mano de obra, en un proceso que la autora denomina "domesticación estatal del trabajo". El Estado, además de ente recaudador y punitivo (y justamente para poder serlo) debió construir una idea de sociedad productiva, eliminando de ella aquellos sujetos que pudieran ser criminalizados por no adaptarse. Esto también contribuyó a la consolidación de un mercado y de una matriz económica de trabajo y explotación.

Otro gran aporte para entender el Estado en su conformación lo constituye el libro de Potthast, ${ }^{8}$ que permite indagar sobre las formas en las que el mismo intentó intervenir en la sociedad, más específicamente en su organización social primigenia, la familia. Además de demostrar las diversas interacciones (legales, normativas, jurídicas, económicas) entre la familia y la unidad estatal, enfatiza las resistencias de la sociedad en la adopción de normativas restrictivas. Es decir, la construcción de un conjunto social, que más allá de ser o no ciudadano, se relaciona con el Estado a partir de aceptar o rechazar mandatos o proscripciones.

En un artículo anterior, ${ }^{9}$ indagamos la conformación del Estado durante el tiempo de Carlos Antonio López, encontrando en su propuesta elementos transicionales entre una idea autoritaria y centralista del poder y una con ciertas tendencias a la subdivisión (aunque muchas veces no haya pasado del plano descriptivo normativo) del poder.

Por su parte, Pastore recolectó y sistematizó la información económica disponible para concluir que el Estado paraguayo del Siglo XIX no fue más que "la prolongación del mercantilismo colonial, del absolutismo, y del militarismo" ${ }^{10}$ y que esas características fueron incluso acentuadas.

Realizan una valiosa apuesta similar, desde un abordaje histórico de las formas estatales, políticas y sociales para el período posterior a la Guerra de la Triple Alianza (18641870) Abente Brun, ${ }^{11}$ Brezzo, ${ }^{12}$ Caballero Campos, ${ }^{13}$ Chartrain, ${ }^{14}$ indagando sobre la

\footnotetext{
${ }^{6}$ Guerra, Francois-Xavier. Modernidad e independencias. Ensayos sobre las revoluciones hispánicas. (Madrid: Mapfre, 1992).

${ }^{7}$ Rivarola, Milda. Vagos, pobres y soldados. La domesticación estatal del trabajo en el Paraguay del Siglo XIX. (Asunción: Servilibro, 2010).

${ }^{8}$ Potthast, Barbara. ¿"Paraíso de Mahoma" o "País de las Mujeres"? El rol de la familia en la sociedad paraguaya del siglo XIX. (Asunción, ICPA, 1996).

9 López, Magdalena. "El Estado en Paraguay durante el gobierno de Carlos Antonio López. Una propuesta teórica-histórica”. Revista Páginas, vol. 11, no 25 (2019). [https://doi.org/10.35305/rp.v11i25.326].

${ }^{10}$ Pastore, Mario H. "State-led "industrialization": the evidence on Paraguay, 1852-1870". Journal of Latin American Studies, vol 26, no 2 (1994): 322. [https://www.jstor.org/stable/157945]. Traducción propia

${ }^{11}$ Abente Brun, Diego. "Foreign Capital, Economic Elites and the State in Paraguay during the Liberal Republic (1870-1936)". Journal of Latin American Studies vol 21, n 1-2 (1989): 61-88.
} 
reconstrucción del Paraguay, y las viejas y nuevas estrategias y tensiones políticas. A partir de allí, también se puede reconstruir la identidad del Estado.

Rescatamos el aporte de Luis Galeano, en su libro La Hegemonía de un Estado Débil, ${ }^{15}$ que indaga sobre la construcción y consolidación del Estado a partir de sus tensiones con la sociedad, revisando el rol del campesinado y los terratenientes latifundistas, la cristalización de los intereses políticos en partidos y la de una matriz económica excluyente y concentrada.

Como podemos ver, todos estos trabajos han aportado a comprender el Estado en Paraguay, indagando elementos específicos que permitiesen comprender la forma y los matices que fue adquiriendo.

Para Faletto, "el Estado expresa en todos los casos el conjunto de relaciones económicas, sociales y, especialmente, de poder que se dan en una sociedad". ${ }^{16}$ Debatiendo con Ozlack, Lechner plantea que el Estado excede a una mera unificación territorialadministrativa y que “como la empresa es más que una agregación de 'factores', así el estado es más que la suma de aparatos coercitivos, económicos e ideológicos". ${ }^{17}$

Por esta causa y contemplando todas estas complejidades, en este trabajo analizaremos las tres constituciones, rastreando los siguientes cuatro ejes, previamente enumerados: la organización del poder (división, institucionalización); la construcción de ciudadanía y/o de actores sociales identificados con derechos; la relación con la Iglesia; y la matriz productiva y de propiedad privada. Intentaremos a partir de ellos aprehender las formas de Estado materializadas en ellas.

La metodología propuesta es cualitativa de estudio de caso y propone una visión interpretativa de los textos constitucionales, abordados a partir de los ejes mencionados y con la intención de distinguir modelos de Estado e imaginarios de sociedad que se derivan, pero también que inspiran esas normativas. Esto lo hacemos con la convicción de que las opciones constitucionales de una sociedad, como las denomina Gargarella, ${ }^{18}$ son importantes para caracterizarla y no simples formaciones superficiales.

\footnotetext{
12 Brezzo, Liliana. "Reconstrucción, poder político y revoluciones (1870-1920)". En Historia del Paraguay. Coordinado por Ignacio Telesca. (Asunción: Taurus, 2010), pp. 199-224.

${ }^{13}$ Caballero Campos, Herib. El País ocupado. (Asunción: El Lector, 2013).

${ }^{14}$ Chartrain, François. La iglesia y los partidos en la vida política del Paraguay desde la Independencia. (Asunción: CEADUC, 2013).

${ }^{15}$ Galeano, Luis. La Hegemonía de un Estado Débil. (Asunción: CPES, 2009).

${ }^{16}$ Faletto, Enzo. "La especificidad del Estado latinoamericano". Revista de la CEPAL, no 38 (1989): 69.

${ }^{17}$ Lechner. "Presentación”. Pp. 17.

${ }^{18}$ Gargarella, Roberto. La Sala de máquinas de la Constitución. Dos siglos de constitucionalismo en América Latina (1810-2010). (Buenos Aires: Katz Editores, 2015).
} 
Entendemos que el juego es de doble influencia: así como las Constituciones representan un contexto de ideas y de relaciones de fuerza, también están influenciadas por ese contexto y son resultado (al tiempo que causantes) de ese entramado.

En este trabajo, presentaremos, antes de cada Constitución, un breve repaso histórico que nos permita contextuar su sanción. Luego de cada descripción histórica, desplegaremos el análisis de las expresiones normativas a través de las cuatro lentes propuestas. Finalizaremos con unas conclusiones comparativas.

\section{La Ley de 1844, la Constitución de 1870 y la Carta de 1940}

Gargarella $^{19}$ propone que existen cinco momentos constitucionales en la región: primero, el llamado primer constitucionalismo latinoamericano, que va de 1810 a 1850 ; el segundo, desde 1850 a 1890, denominada constitucionalismo de fusión o período fundacional; el tercero, de 1890 a 1930, es el de la crisis del modelo de constitucionalismo post-colonial; el cuarto, desde 1930 hasta mediados del Siglo XX, definido como constitucionalismo social; y el último, hasta el cambio de siglo, se desarrolla el momento denominado nuevo constitucionalismo latinoamericano. Las tres constituciones que analizaremos en este trabajo responden temporalmente a los tres primeros períodos (1844, 1870 y 1940). Es interesante indicar que los modelos de análisis constitucionales más difundidos en América Latina, como por ejemplo el planteado por el mismo Gargarella, ${ }^{20}$ no aplican linealmente al caso paraguayo, pues los "tipos ideales" esbozados (constitucionalismo radical, constitucionalismo conservador y constitucionalismo liberal) presentan en Paraguay modelos hibridados y diferenciales. El mismo autor refiere, por ejemplo, a la Constitución de 1870 como una fusión por combina elementos liberales y conservadores. ${ }^{21}$

La historia paraguaya invita al ejercicio de exégesis y análisis constitucional e histórico combinando una visión regional como la esbozada por esos trabajos, pero también cotejada con la historia específica del territorio, sus disputas y sus clivajes.

A continuación analizaremos las tres constituciones, en sus tres contextos sociohistóricos, haciendo foco en los cuatro ejes presentados en el apartado metodológico: la organización del poder; los actores sociales identificados y sus derechos; la relación con la Iglesia; y los perfiles de la matriz productiva y la propiedad de la tierra.

\footnotetext{
${ }^{19}$ Gargarella. La Sala de máquinas...

${ }^{20}$ Gargarella, Roberto, Los fundamentos legales de la desigualdad. El constitucionalismo en América (17761860). (Madrid: Siglo XXI Editores, 2005); y Gargarella. La Sala de máquinas...

${ }^{21}$ Gargarella. La Sala de máquinas...
} 


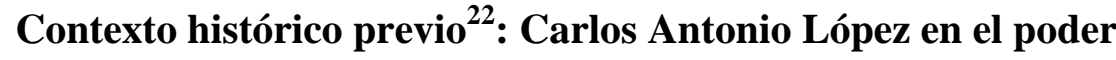

En 1811, Paraguay inició su proceso de independencia de España y también de otros poderes regionales, como Buenos Aires. El Doctor Francia gobernó el Paraguay desde 1814 (cuando comenzó la Dictadura Suprema que sería Perpetua dos años más tarde) hasta 1840:

"mediante una dictadura con un monopolio del poder, donde no existió división de poderes y la mayor preocupación estaba puesta en evitar una invasión de las potencias vecinas que estaban, al igual que Paraguay, ejerciendo un poder conflictivo sobre sus territorios y disputando límites geográficos y administrativos. Sobresalió especialmente la centralidad del poder, la carencia de un sistema normativo y legal que inaugurase un nuevo orden estatal y la reproducción de una sustancial cantidad de prácticas y ejercicios coloniales de la autoridad". 23

En 1840, año de la muerte del Dictador Perpetuo, Paraguay enfrentó el problema de la sucesión, tras una absoluta concentración de poder en una sola persona que no tenía descendencia ni había generado los mecanismos institucionales para su reemplazo. Se ensayaron diferentes formas de gobierno hasta que, en 1841, un Congreso inauguró el Consulado encabezado por Carlos Antonio López y Mariano Roque Alonso, que se extendería hasta 1844, cuando la figura de López lograse monopolizar el poder y ser nombrado Presidente.

En trabajos previos, ${ }^{24}$ indicamos que el período de Gobierno del primer López fue un momento de consolidación política, estatal, económica e institucional del Paraguay, con particularidades en cuanto a la forma de la organización productiva, que desarrolló avances no sólo técnicos y tecnológicos y de organización interna, sino también de relaciones exteriores y de conquista de la aceptación de Paraguay como un Estado independiente por parte de otras naciones del mundo.

López sostuvo el poder frente a vertientes que reclamaban cambios más radicales, y fue construyendo un andamiaje legal e institucional que además de consolidar una idea de Estado, le iban autolegitimando.

\footnotetext{
${ }^{22}$ Para un recorrido pormenorizado por la historia de Paraguay, ver la obra coordinada por Ignacio Telesca, Nueva Historia del Paraguay. Asunción: Sudamericana, 2020. También se recomienda la lectura del Galeano, La Hegemonía de un Estado Débil..., dado que aborda el período histórico aquí relevado.

${ }^{23}$ López. El Estado en...:3.

${ }^{24}$ López. El Estado en...
} 
Tras un ejercicio presidencial extendido, López solicitó reformar la Constitución en 1856 que analizaremos para introducir modificaciones en los artículos referentes a los requisitos del Presidente (habilitar la candidatura de militares y disminuir la edad mínima obligatoria para el cargo). Con estas modificaciones, el hijo de López, Francisco Solano, quien había tenido un rol central en el desarrollo de la política exterior del país, podría ser elegido para la Presidencia. Esto sucedió luego de la muerte de Carlos Antonio en 1862.

\section{Ley de Administración Pública de 1844}

Si bien no adquirió la nomenclatura de Constitución, la Ley que establece la Administración Política de la República del Paraguay y demás que en ella se contiene es considerada como la primera del Paraguay. Entre otros elementos, en ella se establece y explica la estructuración del andamiaje político, de la división de poderes y de la organización cívico-política del Estado.

Por su contexto y por su formato, es más compleja de comparar con las dos Constituciones siguientes, pero hacerlo permite, más allá de los desafíos, poder dar cuenta de las visiones de Estado y de sus comparaciones.

Un elemento a remarcar es que la Ley de 1844 es que no desarrolla completamente los 4 ejes que hemos seleccionado para comparar, aunque si lo hace mediante la indicación de respaldar decretos previos en los que sí se reglamentaban sobre esas temáticas. En el artículo 11 del Título X, correspondiente a las Ordenanzas Generales, la Constitución dictamina: "Se ratifican las leyes y decretos sancionados por el Soberano Congreso de 25 de Noviembre de $1842 " .{ }^{25}$ Refiere a la reunión del Congreso convocada para dicha fecha, cuya acta escrita (fechada el día siguiente), además, indica: “apruébense todos los demás decretos publicados por el Supremo Gobierno desde su instalación hasta esta fecha (...)" ${ }^{26}$ Esto determina un diagrama reglamentario en el que cual una Ley, remite a la anterior para aprobar un conjunto amplio de decretos, y dentro de los mismos, hay uno que, con el mismo propósito, redirecciona a otra ley anterior.

De los decretos previos recuperados algunos remiten a sucesos históricos muy particulares (construcciones de catedrales, habilitación de cementerios, aumento de pago a determinados funcionarios) y otros, en cambio, permiten comprender la visión de lo social, lo

\footnotetext{
${ }^{25}$ Artículo 11. Título X. Ordenanzas Generales. Ley que establece la Administración Política de la República del Paraguay y demás que en ella se contiene. 16 de Marzo de 1844

${ }^{26}$ Artículo Décimo. Aprobación del Mensaje del Supremo Gobierno de la República del Paraguay al Soberano Congreso Nacional. 26 de noviembre de 1842. N 27.
} 
económico y lo político del contexto. Son leyes que un Congreso declaró, a partir de los Mensajes dados por los Cónsules que reportaban sus decisiones ante ese órgano. Es decir, en cierta forma, fue un proceso de jerarquización legal de las decisiones tomadas previamente por López y Mariano Roque Alonso.

Otro elemento que se distingue es que la Constitución se sanciona y luego, fundado en la legitimidad que de ella emana, Carlos Antonio López es nombrado Presidente de la República. Sin embargo, las normas anteriores que recupera y reafirma la Ley de 1844 son del período en el que el gobierno era ejercido por el Consulado, conformado por Mariano Roque Alonso y el mismo López. Esto abre posibles indagaciones sobre la articulación de estas dos formas de gobierno y, sobre todo, las continuidades que presentan y la hipótesis de que la presencia de López sea el factor de equilibrio en el paso de un modelo a otro.

Proponemos previamente revisar la estructura general de la Ley de 1844. El documento se divide en X títulos consecutivos: De la Administración General (4 artículos); Del Congreso o Legislatura Nacional (10 artículos); De las atribuciones del Congreso Nacional (12 artículos); Del Poder Ejecutivo Permanente (5 artículos); De la elección del Presidente de la República (5 artículos); Distintivos del Presidente de la República (4 artículos); De las atribuciones del Presidente de la República (30 artículos); De los Ministros secretarios (4 artículos); Del Consejo de Estado (12 artículos) y Ordenanzas Generales (13 artículos).

Si se la analiza desde su disposición, es evidente una preminencia de artículos en el Título VII, De las atribuciones del Presidente, lo cual podría indicar algo que se confirma luego de la exégesis del documento: la Constitución propone un Poder Ejecutivo unipersonal con poder y potestades muy prominentes.

Respecto al eje inicial, esta Ley establece separación de poderes indicando que "la Administración General de la República se expedirá en adelante por un Congreso o Legislatura Nacional de Diputados Representantes de la República; por un Presidente en quien resida el Supremo Poder Ejecutivo y por los Tribunales y Jueces establecidos por ley del Soberano Congreso Extraordinario de 25 de Noviembre de 1842", ${ }^{27}$

El Congreso se componía de doscientos diputados (disminuyendo la cantidad indicada en años anteriores) y se convocaba cada cinco años. Entre las tareas centrales de este órgano estaba la de legislar y la de elegir al Presidente, evaluando luego su desarrollo.

En cuanto al Presidente, debía ser paraguayo natural, de 45 años de edad mínima y poseedor de un capital propio (de ocho mil pesos) y de un conjunto de virtudes (honradez,

\footnotetext{
27 Artículo 1. Título I. De la Administración General. Ley que establece la Administración Política de la República del Paraguay y demás que en ella se contiene. 16 de Marzo de 1844.
} 
capacidad, patriotismo, buena conducta moral). Además, debía pertenecer al fuero común, lo que constituye un elemento muy original pues inhabilitaba el acceso del clero y de personas de carrera militar al Poder Ejecutivo (algo que es modificado en la reforma de 1856). El cargo duraba diez años y se obtenía a partir de la mayoría de cuatro votos sobre la mitad del Congreso.

Si bien la Ley de 1844 no solicitaba que el Presidente fuese católico, el ingreso al ejercicio del cargo se hacía mediante la jura "por Dios Nuestro Señor y estos Santos Evangelios”, con el compromiso de proteger a la Religión Católica Apostólica Romana, única del Estado. ${ }^{28}$

El Presidente podía también nombrar Ministros Secretarios de Estado $^{29}$ y podía convocar un Consejo de Estado eventual o temporalmente, conformado por el prelado diocesano, y dos Jueces de la Magistratura y tres "ciudadanos de capacidad" seleccionados por el Ejecutivo.

El Poder Ejecutivo quedaba casi íntegramente centralizado en una persona, pudiendo elegir no convocar a Ministros ni tener que dar cuenta de sus decisiones más allá de la comparecencia quinquenal ante el Congreso.

En cuanto a la autonomización de una práctica judicial y punitiva, la Constitución afirmaba la aprobación del Estatuto Provisorio de la Administración de Justicia y el Decreto Reglamentario de Policía (ambos aprobados en la Ley de 1842). Si bien no se constituyeron en un sistema judicial completamente ajeno al poder centralizado del Presidente, sí dieron cuenta de la necesidad contextual de institucionalizar la justicia, sobre todo por el grado de complejidad que iban ganando los procesos y las demandas, a medida que se expandían los modelos productivos y económicos y crecían los asentamientos.

Indagando a partir del segundo eje, el de la identificación de actores sociales con derechos, se advierte un elemento interesante y es la vaga referencia a estos actores, algo que evidenciamos en trabajos anteriores. ${ }^{30}$ Guerra $^{31}$ indica que en las primeras disposiciones legales de América Latina no se pensaba al individuo, sino a las comunidades y, más

\footnotetext{
${ }^{28}$ Artículo 3. Título IV. Del Poder Ejecutivo Permanente. Ley que establece la Administración Política de la República del Paraguay y demás que en ella se contiene. 16 de Marzo de 1844.

${ }^{29}$ Artículo 1. Título VIII. De los Ministros secretarios. "Cuando el Presidente de la República lo creyere conveniente, podrá nombrar uno o más Ministros Secretarios de Estado, o reunir accidentalmente en un solo Ministerios los Departamentos de Gobiernos y de Relaciones Exteriores". Ley que establece la Administración Política de la República del Paraguay y demás que en ella se contiene. 16 de Marzo de 1844.

${ }^{30}$ López. El Estado en...

${ }^{31}$ Guerra, François-Xavier. "El Soberano y su reino. Reflexiones sobre la génesis del ciudadano en América Latina”. En Ciudadanía política y formación de las naciones: Perspectivas históricas, coordinado por Hilda Sábato. (México: FCE, 1999).
} 
específicamente, a las familias. Esta interpelación no queda tan clara en los documentos de Carlos Antonio López. En la Constitución se establecía la igualdad ante la ley de todos los hombres, indicando que la ley debe "favorecer igualmente al poderoso que al miserable"; 32 y que todos los habitantes tenían derecho a que sus quejas fueran escuchadas por el Supremo Gobierno de la Nación. ${ }^{33}$ Además se aprueba la Academia Literaria como base del Colegio Nacional, quedando el Estado responsabilizado del sostén de mantenimiento, marcando un embrionario derecho a la educación.

Sin embargo, tanto para abrir establecimientos educativos o de ciencia, como para establecer imprenta de particulares, se debía solicitar el permiso y revisión del Supremo Gobierno; lo cual da cuenta de muy poco desarrollo de la libertad de expresión. Las limitaciones de las garantías cívicas se evidencian aún más en la aprobación de la pena de muerte para "Todo el que atentare o prestare medios de atentar contra la Independencia de la República o contra la presente ley fundamental". ${ }^{34}$

Paralelamente, la Ley de 1844 confirma la libertad de vientres, con la especificación del artículo 2 del Decreto sobre Libertad de Vientres de las Esclavas, del 24 de noviembre de $1842, \mathrm{~N}^{\mathrm{o}} 24$, donde se planteaban que los libertos debían servir a sus señores como patronos de los libertos hasta los 25 y 24 años de edad, varones y mujeres respectivamente. ${ }^{35}$

Otro rasgo de todos estos textos, es la intervención del Gobierno sobre ciertos grupos sociales a los que encuentra en extrema vulnerabilidad - desgraciados, pobres, desmejorados - e interviene a partir de resolver la situación específica de dichos grupos sociales. En su Mensaje ante el Congreso, del 24 de noviembre de 1842, luego aprobado por los Diputados, López identifica a un grupo de "indios capaces y de servicios" a los que solicitaba se les den las tierras y haciendas de las comunidades en las que viven, libres de gravamen. Lo mismo realiza sobre un grupo de esclavos ya envejecidos. El Estado aparece más como un interventor focalizado que interpreta y resuelve situaciones acuciantes de la población, que como el promotor de derechos colectivos inalienables.

Las referencias sobre el eje tercero en el cuerpo de la Ley, la relación con la Iglesia Católica, no son tan numerosas pero revisten de gran importancia. En una parte indica que es

\footnotetext{
${ }^{32}$ Artículo 2. Título X. Ordenanzas Generales. Ley que establece la Administración Política de la República del Paraguay y demás que en ella se contiene. 16 de Marzo de 1844.

${ }^{33}$ Artículo 3. Título X. Ordenanzas Generales. Ley que establece la Administración Política de la República del Paraguay y demás que en ella se contiene. 16 de Marzo de 1844.

${ }^{34}$ Artículo 13. Título X. Ordenanzas Generales. Ley que establece la Administración Política de la República del Paraguay y demás que en ella se contiene. 16 de Marzo de 1844.

35 Para más información sobre este período, recomendamos el artículo de Ignacio Telesca "Sociedad y afrodescendientes en el proceso de independencia del Paraguay" en Negros de la Patria, editado por Silvia Mallo e Ignacio Telesca, (Buenos Aires: SB, 2010).
} 
una atribución del Presidente ejercer "el patronato general respecto de las iglesias, beneficios y personas eclesiásticas con arreglo a las leyes: nombra los obispos y los miembros del Senado eclesiástico" y también "puede celebrar concordatos con la Santa Sede Apostólica; conceder o negar su beneplácito a los decretos de los concilios y cualesquiera otras constituciones eclesiásticas; dar o negar el exequátur a las bulas o breves Pontificáis, sin cuyo requisito nadie las pondrá en cumplimiento". 36

También se pueden recuperar distinciones de esta relación en las referencias previas que la misma Constitución respalda. Por ejemplo, en el Artículo Vigésimo Quinto, el Congreso había sancionado "queda prohibido conceder o permitir en el territorio de la República la tolerancia de sectas religiosas o la libertad de cultos", 37 en clara prioridad del catolicismo y acorde al contexto en el que Carlos Antonio López intentaba recuperar relación con el Vaticano y desandar el camino más secular de su antecesor, Rodríguez de Francia. En la misma línea, restableció el diezmo destinándolo exclusivamente para financiar a la Iglesia y a los miembros eclesiásticos. ${ }^{38}$

Finalmente, la Constitución de 1844 no habla explícitamente de una matriz productiva ni de un modelo de propiedad, aunque indica que es atribución del Congreso "fijar la ley, valor, peso y tipo de la moneda" y "reglar el comercio interior y exterior", 39 y del Presidente "abrir puertos de comercios (...)". 40

Sí podemos rastrear algunos elementos en los textos anteriores, que indican cierta trayectoria para lograr un mercado estable y dinámico, así como una fuente de financiación para el ejercicio estatal. En esta línea se encuentra el permiso en 1842 de la primera acuñación de moneda y la aprobación de impuestos específicos y sellados y del Reglamento de Aduana.

\section{La antesala de la nueva Constitución}

El gobierno del mariscal López se vio atravesado por las amenazas de guerra y la concreción del enfrentamiento bélico contra los tres Aliados: Argentina, Brasil y Uruguay. La

\footnotetext{
${ }^{36}$ Artículo 16 y 17, respectivamente. Título VII. De las atribuciones del Presidente de la República. Ley que establece la Administración Política de la República del Paraguay y demás que en ella se contiene. 16 de Marzo de 1844.

37 Artículo Vigésimo Quinto. Aprobación del Mensaje del Supremo Gobierno de la República del Paraguay al Soberano Congreso Nacional. 26 de noviembre de 1842 . No 27.

${ }^{38}$ Decreto que reestablece la ley de Diezmos. № 25. 24 de Noviembre de 1842.

${ }^{39}$ Artículo 7 y 10, respectivamente. Título III. De las atribuciones del Congreso Nacional. Ley que establece la Administración Política de la República del Paraguay y demás que en ella se contiene. 16 de Marzo de 1844.

${ }^{40}$ Artículo 26. Título VII. De las atribuciones del Presidente de la República. Ley que establece la Administración Política de la República del Paraguay y demás que en ella se contiene. 16 de Marzo de 1844.
} 
guerra significó un gran deterioro de la economía, la infraestructura, la población y la autonomía de Paraguay. ${ }^{41}$

Tras perder la Guerra Grande, ser responsabilizado por los Aliados de las deudas materiales y ser territorialmente ocupado, las fuerzas triunfantes apoyaron el establecimiento de un Triunvirato, luego reemplazado por Presidentes que duraron muy poco en el cargo, en un claro escenario de inestabilidad, desequilibrio y violencia política. Si bien este proceso de sucesión reemplazo presidencial constante no era nuevo, en este momento se realizaba en el contexto de las tensiones que las postrimerías de la guerra habían dejado, en un Estado y una nación devastados: pérdida poblacional y territorial, consecuencias económicas, desguace de un modelo productivo previo, imposición de las condiciones para la paz.

Cirilo Rivarola, quien aparece como firmante del Decreto que pone en vigencia la Constitución de 1870, fue presidente provisorio en el momento de la Sanción de la Carta. Sin embargo, estuvo muy poco tiempo en el cargo y la Carta no refleja el pensamiento y planificación de este hombre. Entre 1870 y 1886 rotan presidentes que no logran completar un período, hasta la llegada de Bernardino Caballero, que da inicio al ciclo del Partido Colorado, que describiremos en un apartado posterior.

Por los años que el territorio queda ocupado, se fueron dando forma y desarrollando las doctrinas de los dos partidos políticos más importantes del país hasta la actualidad: la Asociación Nacional Republicana (ANR o Partido Colorado) y el Partido Liberal.

\section{Constitución de 1870}

La Constitución de 1870, considerada la primera Constitución liberal de Paraguay, se sanciona luego de la tragedia de la Guerra Grande para el Paraguay y en un contexto de ocupación.

El texto de 1870 tiene notorias similitudes con la Constitución argentina de la época, aunque algunos autores la consideran más conservadora por preservar el unitarismo. ${ }^{42}$

En su estructura formal posee dos partes, la Primera contiene tres Capítulos: Declaraciones generales (17 artículos); Derechos y garantías (17 artículos); y De la Ciudadanía (7 artículos). La Segunda Parte tiene doce Capítulos: Del Poder Legislativo (1

\footnotetext{
${ }^{41}$ Por cuestiones de extensión, no abordaremos aquí las consecuencias de la Guerra Grande para Paraguay, pero recomendamos los trabajos de Luc Capdevila, Una Guerra Total, Paraguay 1864-1870, (Buenos Aires: SB, 2010); y de Brezzo, Reconstrucción, poder político y revoluciones...

42 Gargarella. 200 años de...., y Mendonca, Juan Carlos. \& Mendonca, Daniel. Breve historia del constitucionalismo paraguayo. (Asunción: Centro de Estudios Constitucionales, 2009).
} 
artículo); De la Cámara de Diputados (8 artículos); Del Senado (8 artículos); Disposiciones comunes a ambas Cámaras (14 artículos); Atribuciones del Congreso (1 artículo); De la Formación y sanción de las leyes (5 artículos); De la Comisión permanente (9 artículos); Del Poder Ejecutivo, de su naturaleza, duración y elecciones (15 artículos); Atribuciones del Poder Ejecutivo (2 artículos); De los Ministros del Poder Ejecutivo (6 artículos); Del Poder Judicial y sus atribuciones (12 artículos); de la Reforma de la Constitución (4 artículos). Además tiene un último segmento de Adición que suma 4 artículos más.

Respecto al primer eje, se advierte una división del poder más intencional e institucionalizada que en la Constitución de 1844. Es interesante que el liberalismo legal sea rastreado en Paraguay, no tanto como una resistencia interna al conservadurismo, como indica Gargarella, sino mediado por una Constitución erigida en un escenario posbélico internacional de daños inconmensurables para el Estado y la sociedad, es decir, un proceso mucho más regional que doméstico.

Esta nueva legalidad vino de la mano de establecer constitucionalmente que Paraguay era una República libre e independiente, una e indivisible, democrática y representativa y que la soberanía residía esencialmente en la Nación. ${ }^{43}$

El carácter representativo está sustentado en que "el pueblo no delibera ni gobierna sino por medio de sus representantes y autoridades creadas por esta Constitución". 44 La representación soberana del Pueblo quedaba en manos del Congreso. ${ }^{45}$

El Ejecutivo quedaría en manos del Presidente de la República del Paraguay, un paraguayo natural, católico (una incorporación que no existía en la de 1844), de una edad mínima de 30 años, que ejercería el cargo por cuatro años, renovable sólo con dos períodos de intervalo.

El proceso de elección de Presidente y Vice, ya no recaerá en el Congreso, sino que será mediado por una junta de electores erigida por cada distrito electoral a partir de voto directo, de la que no podía formar parte ningún diputado ni senador ni empleado a sueldo. ${ }^{46}$

En un intento por recortar el Poder Ejecutivo, redistribuye las atribuciones entre el Presidente y el Congreso, y también determina una subdivisión dentro del mismo Ejecutivo, indicando que los Ministros serían cinco: Interior; Relaciones Exteriores; Hacienda; Justicia-

\footnotetext{
${ }^{43}$ Artículo 1 y 2. Capítulo I. Declaraciones Generales. Constitución de la República del Paraguay. 24 de Noviembre de 1870.

${ }^{44}$ Artículo 31. Capítulo II. Derechos y Garantías. Constitución de la República del Paraguay. 24 de Noviembre de 1870 .

${ }^{45}$ Artículo 103. Capítulo XII. Atribuciones del Poder Ejecutivo. Constitución de la República del Paraguay. 24 de Noviembre de 1870.

${ }^{46}$ Artículo 94. Capítulo XI. Del Poder Ejecutivo. De su naturaleza, duración y elección. Constitución de la República del Paraguay. 24 de Noviembre de 1870.
} 
Culto e Instrucción pública; y Guerra y Marina. ${ }^{47} \mathrm{Si}$ bien todos eran elegidos por el Presidente, es interesante el surgimiento de estas figuras estables, porque involucran un aumento en el grado de profesionalización y especialización del ejercicio del poder. En esta misma línea, también se integra la figura de Vicepresidente.

El Poder Legislativo se compondrá por dos Cámaras, una de Diputados y otra de Senadores, que conformarían el Congreso. Los miembros debían ser ciudadanos naturales, y los diputados tener al menos 25 años de edad, mientras los Senadores, un mínimo de 28. Los primeros ejercían el cargo por cuatro años, con posibilidad de reelección y renovación parcial (la mitad) cada dos años, y los segundos por seis, reelegibles, y con renovación parcial de un tercio bienal.

El Congreso no podía cederle facultades extraordinarias al Ejecutivo ni ninguna suma de poder que atentase contra la vida, el honor o la propiedad de los habitantes, ${ }^{48}$ siendo estos tres elementos presentados como iguales y debiendo ser protegidos de quedar a merced del Gobierno. La Constitución introduce un conjunto de protecciones - compatibles con la idea de fueros - a los representantes para que puedan tener garantías y libertades en el ejercicio de sus funciones.

La Constitución establece el Poder Judicial liderado por un Superior Tribunal de Justicia conformado por tres miembros y todos los jueces inferiores. Si bien los elegía el Presidente, sólo el Poder Judicial podía decidir en actos contenciosos, sin ninguna capacidad del Presidente para tomar atribuciones judiciales, excepto la de reservarse el derecho a indultar o conmutar penas, previo informe al Tribunal.

Es interesante resaltar que la Constitución de 1870 permitía a toda persona a arrestar a un delincuente en el momento de la ejecución del delito y llevarlo ante los jueces competentes. ${ }^{49}$ Este artículo es complejo pues habilita un conjunto de opciones que pueden violar la integridad de las personas. Esto nos invita a pasar al siguiente lineamiento de análisis.

Respecto al eje segundo, sobre los derechos y el reconocimiento de grupos sociales, encontramos una ampliación significativa respecto a la Constitución de 1844, ampliación que es esperable dado el encuadre liberal de esta Carta. Por ejemplo, estableció que la educación primaria fuese obligatoria y de atención preferente del Gobierno. Es interesante que no

\footnotetext{
${ }^{47}$ Artículo 104. Capítulo XIII. De los Ministros del Poder Ejecutivo. Constitución de la República del Paraguay. 24 de Noviembre de 1870.

${ }^{48}$ Artículo 13. Capítulo I. Declaraciones Generales. Constitución de la República del Paraguay. 24 de Noviembre de 1870.

${ }^{49}$ Artículo 28. Capítulo II. Derechos y Garantías. Constitución de la República del Paraguay. 24 de Noviembre de 1870 .
} 
incluye explícitamente que deba proveerla, aunque sí "promover por todos los medios posibles la instrucción de los ciudadanos". ${ }^{50}$

Todos los habitantes de la República (ya no únicamente los ciudadanos) contaban con diferentes derechos, detallados en el Artículo 18, entre los que se encuentran el de publicar sus ideas en la prensa sin censura previa, ${ }^{51}$ declarándose a la libertad de prensa inviolable e imposible de coartar mediante ley.

Todos los ciudadanos tenían derecho al sufragio, desde los 18 años de edad, y este se perdía por un conjunto de causas, siendo la más importante para nuestra investigación la número 2: "por ser soldado, cabo o sargento de tropa de línea o guardia Nacional movilizada de mar y tierra bajo cualquier denominación que sirvieren. (...)". 52

La pena de muerte ya no aparece en la Constitución, pero se repone el delito de "traición contra la Nación", 53 definido como tomar las armas contra ella o asistir a los enemigos de la misma, sobre el que el Congreso fijará la pena por ley.

Sobre el tercer eje, la relación con la Iglesia, esta Constitución es relativamente más interreligiosa que la de 1870, dado que propone una apertura moderada hacia la aceptación de otros cultos. En sus comienzos, afirmaba "la Religión del Estado es la Católica, Apostólica, Romana; debiendo ser paraguayo el Jefe de la Iglesia; sin embargo, el Congreso no podrá prohibir el libre ejercicio de cualquiera otra religión en todo el territorio de la República". ${ }^{54} \mathrm{El}$ presidente, y también el vice, debían profesar el catolicismo. ${ }^{55}$

Conserva, al igual que la Constitución de 1844 la potestad de ejercer "los derechos del Patronato Nacional de la República en la presentación de Obispos para la Diócesis de la Nación a propuesta en terna del Senado, de acuerdo con el Senado Eclesiástico, o en su defecto, del Clero Nacional, reunido" y conceder el pase o retener "los decretos de los Concilios, las Bulas, Breves y Rescriptos del Sumo Pontífice con acuerdo del Congreso". 56

\footnotetext{
${ }^{50}$ Artículo 8. Capítulo I. Declaraciones Generales. Constitución de la República del Paraguay. 24 de Noviembre de 1870.

${ }^{51}$ Artículo 18. Capítulo II. Derechos y garantías. Constitución de la República del Paraguay. 24 de Noviembre de 1870.

52 Artículo 39. Capítulo III. De la ciudadanía. Constitución de la República del Paraguay. 24 de Noviembre de 1870.

${ }^{53}$ Artículo 119. Capítulo XIV. Del Poder Judicial y sus atribuciones. Constitución de la República del Paraguay. 24 de Noviembre de 1870.

${ }^{54}$ Artículo 3. Capítulo I. Declaraciones Generales. Constitución de la República del Paraguay. 24 de Noviembre de 1870 .

${ }^{55}$ Artículo 89. Capítulo XI. Del Poder Ejecutivo. De su naturaleza, duración y elecciones. Constitución de la República del Paraguay. 24 de Noviembre de 1870.

56 Artículo 102. Capítulo XII. Atribuciones del Poder Ejecutivo. Constitución de la República del Paraguay. 24 de Noviembre de 1870.
} 
Por último, analizando el cuarto eje en la Constitución de 1870, notamos que el texto obliga al Gobierno a generar relaciones comerciales y de paz con las naciones extranjeras, ${ }^{57}$ de manera más explícita que la de 1844, que esbozaba la idea de hacerlo en la medida en la que fuese necesario.

Además, esta constitución establece que la propiedad es inviolable y que ningún habitante puede ser privado de ella. Como indicamos en el primer eje, el Ejecutivo no podía atentar contra la propiedad de los habitantes, que es puesta en el mismo nivel que su vida y honor.

A diferencia de la Constitución de 1844, la de 1870 indica que los puertos comerciales deben ser habilitados por el Congreso ${ }^{58}$ y una amplia variedad de potestades económicas son puestas en manos del órgano legislativo.

\section{Los prolegómenos de la Carta de 1940: crisis desde arriba y desde abajo}

Los partidos iniciados en las postrimerías de la Guerra contra la Triple Alianza sirvieron de espacios políticos de socialización y reorganización. Algunos trabajos incluso recuperan la relevancia que tuvieron estos espacios para reagrupar a las elites y constituir bases sociales. ${ }^{59}$ La ANR fue protagonista del ciclo político desarrollado entre los años 1887 y 1904, ${ }^{60}$ caracterizado como relativamente estable. ${ }^{61} \mathrm{El}$ período subsiguiente, que se extendió entre 1905 y 1940, fue especialmente convulso, y estuvo más centralmente liderado por el Partido Liberal, con la irrupción de grandes y fuertes protestas sociales y movimientos revolucionarios. Estos años estuvieron caracterizado por una concatenación de presidencias interrumpidas por golpes de Estado, renuncia o maniobras similares. El período estuvo dotado de un desequilibrio que impedía el desarrollo de un plan de gobierno, con pujas entre los dos partidos (con sus facciones enfrentadas) y tensiones entre partidos, sobre todo en el momento de la Guerra Chica. Es destacable la irrupción del Movimiento Febrerista, comandado por el coronel Rafael Franco, que llegó a la Presidencia por un golpe de Estado en 1936 (perdurando

\footnotetext{
${ }^{57}$ Artículo 12. Incisos 7 y 8, respectivamente. Capítulo I. Declaraciones generales. Constitución de la República del Paraguay. 24 de Noviembre de 1870.

58 Artículo 72. Capítulo VIII. Atribuciones del Congreso. Constitución de la República del Paraguay. 24 de Noviembre de 1870.

${ }^{59}$ Ver Chartrain. La Iglesia y los... 2013; y Brezzo. Reconstrucción, poder político, 2010.

${ }^{60}$ Esta periodización sirve al interés de describir en grandes rasgos la temporalidad de estos tiempos de transición política, pero cada segmento temporal tuvo clivajes internos e interrupciones que deben se indagadas para mayor precisión.

${ }^{61}$ Brezzo. Reconstrucción, poder politico y revoluciones...
} 
hasta 1937) e implementó un conjunto muy amplio de medidas como la creación de Ministerios, Bancos, Facultades y la sanción de un conjunto de leyes con un considerable perfil social.

El fin de este ciclo liberal coincide con la muerte del mariscal Félix Estigarribia, héroe de la Guerra del Chaco (Guerra Chica, por su contraposición a la Guerra Grande, la de la Triple Alianza), que enfrentó a Paraguay con Bolivia entre 1932 y 1935. En 1940, José Félix Estigarribia, del Partido Liberal, sancionó la Constitución que reemplaza la de 1870 y que permite sentar las bases de los posteriores gobiernos autoritarios y dictatoriales de Higinio Morínigo y de Alfredo Stroessner.

Respecto a la Carta Política de 1940, existe perspectivas analíticas, sobre todo de la disciplina del Derecho Constitucional, que no la consideran una Constitución, por las condiciones de irregularidad en las que fue aprobada. Al respecto, Campos Cervera ${ }^{62}$ indica que "la denominación que realmente le corresponde" es la de Carta Política. Por su parte, Mendonça y Mendonça ${ }^{63}$ acuerdan en que es mal llamada Constitución pues fue "impuesta al pueblo por el soberano, en términos inequívocos". Sin embargo, hemos considerado que al erigirse como una norma de normas que compiló formalmente los recursos, estrategias, instituciones y reglamentaciones para gobernar un Estado, tal como indican reconocidos diccionarios jurídicos y de ciencia política, ${ }^{64}$ puede reconocerse como una Constitución, más allá de las condiciones autoritarias en las que fue sancionada. En esta línea, el constitucionalista Lezcano Claude ${ }^{65}$ la incluye junto con la de 1870, la de 1967 y la de 1992 como las constituciones que organizaron al Estado paraguayo entre 1870 y la actualidad; y describe que tras el llamado a reforma constitucional y la convocatoria a una Convención Nacional Constituyente, bajo la presidencia de Estigarribia, en febrero de 1940, se dio una masiva renuncia de los miembros del poder legislativo, por lo que se produjo una autodisolución. Por esta situación y ante la insistencia del presidente de ejercer la reforma, se produjo una centralización total en Estigarribia que sumó funciones legislativas a sus

\footnotetext{
${ }^{62}$ Campos Cervera, Rodrigo. La Constitución de la República del Paraguay, no la Constitución Nacional. Enmienda y Reforma. Generalidades, Necesidad, conveniencia y oportunidad del proyecto. Comentario a la Constitución, Tomo IV. (Asunción, Corte Suprema de Justicia, 2012).

${ }^{63}$ Mendonca \& Mendonca. Breve historia del constitucionalismo

${ }^{64}$ Revisar las definiciones de Frank Bealey en Diccionario de Ciencia Política. Madrid: Istmo. 2003; y Eduardo Ferrer Mac-Gregor, Fabiola Martínez Ramírez y Giovanni Figueroa Mejía en su Diccionario de Derecho Procesal, Constitucional y Convencional. Segunda Edición. (México: UNAM, 2014).

${ }^{65}$ En su texto titulado "Historia Constitucional del Paraguay (Período 1870-2012)", publicado en la Revista Jurídica Universidad Americana, Vol. 3 del año 2012, Luis Lezcano Claude refiere a la de 1940 como Constitución, a pesar de describir minuciosamente las irregularidades del proceso de aprobación y los pormenores del contexto del que emanó esta Carta.
} 
anteriores funciones ejecutivas, justificándose dicha decisión en el contexto político, social y económico de alta tensión y pujas.

El texto constitucional se preparó mediante una Comisión Redactora y fue puesto en vigencia en julio de 1940, sometida a un plebiscito de aprobación en agosto del mismo año, procedimiento que fue realizado para conseguir algún respaldo a la maniobra irregular. Lezcano Claude ${ }^{66}$ indica que la Constitución de 1940 tiene al mismo tiempo influencias fascistas como socialistas y que este mecanismo de votación posterior se desarrolló para intentar darle una legitimidad a la nueva norma constitucional que no emanaba de una Convención como sugería la Constitución anterior (la de 1870).

\section{Constitución de 1940}

El Decreto-Ley No 2242 del 10 de julio de 1940, "Por el cual se promulga la nueva Constitucional Nacional" indica que esta Constitución era parte del intento de "Salvar al país del recrudecimiento de la larga anarquía" que ha castigado a la familia paraguaya. ${ }^{67}$ En este documento, Estigarribia refiere a la amenaza existente respecto al orden y al progreso, a que el país no se encuentra aún en condiciones electorales normales y a que los partidos políticos no colaboran con la democracia legalista, sino que "se resienten de pesadas herencias (...)". 68

De esta forma, el Presidente permite comprender el basamento histórico de la Carta de 1940, que sería más centralista, más concentradora del poder y más inclinada hacia el Ejecutivo que hacia los demás poderes. En esa línea, el mismo decreto explica que la Constitución de 1870 no sirve, pues la nueva "debe responder a nuevas necesidades, a nuevas doctrinas, a nuevos hechos y también a una concepción más nueva del Estado". 69

Estigarribia agrega en el Decreto que era momento de dar una reordenación de las instituciones y una reforma de la estructura del Estado sin ignorar la historia jurídica y la experiencia. Además, remarca "Es asimismo indispensable dotar al Estado de facultades que le habiliten más ampliamente a cumplir sus funciones de realizar el progreso y de intervenir para alcanzar una mayor justicia social, para orientar la economía, para racionalizar la producción y sistematizar coherentemente el trabajo nacional", ${ }^{70}$

\footnotetext{
${ }^{66}$ Lezcano Claude, Historia Constitucional del...

${ }^{67}$ Decreto-Ley N 2.242. Por el cual se promulga la nueva Constitucional Nacional. 10 de julio de 1940.

${ }^{68}$ Decreto-Ley N 2.242...

${ }^{69}$ Decreto-Ley N 2.242...

${ }^{70}$ Decreto-Ley N $2.242 \ldots$
} 
Es, a fines de este trabajo, la mayor descripción de las tareas del Estado y del rol de líder en el proyecto del progreso. Además le atribuye la tarea de organizar la matriz productiva.

La Constitución se divide en diez subtítulos que no revisten nombres específicos (ni partes ni capítulos): Declaraciones generales (18 artículos); Derechos, obligaciones y garantías (19 artículos); Nacionalidad y Ciudadanía (7 artículos); El Poder Ejecutivo (13 artículos); Los Ministros del Poder Ejecutivo (3 artículos); El Consejo de Estado (5 artículos); La Cámara de Representantes (10 artículos); Formación y sanción de leyes (3 artículos), El Poder Judicial (15) y la Reforma de la Constitución (1 artículo).

Dentro del eje de la organización política y la institucionalización del poder, la Constitución de 1940 mantiene muy semejantes los primeros tres artículos, el primero referido al Paraguay como una República libre e independiente, unitaria, que adopta como gobierno una democracia representativa. Sin embargo, existe un cambio que nos resulta importante: en la Carta de 1940 la soberanía ya no reside esencialmente en la Nación (como la anterior) sino en el Pueblo, ${ }^{71}$ quien no delibera ni gobierna sino a través de sus representantes, ${ }^{72}$ como indicaba también la Constitución de 1870 . También se conserva la igualdad ante la ley de todos los habitantes de la República.

El Poder Ejecutivo queda encabezado por el Presidente, que debe ser un ciudadano natural, Católico Apostólico Romano y tener al menos 45 años. El cargo se elige de manera directa en una elección general, dura 5 años y puede ser reelecto una sola vez. ${ }^{73}$ Existe libertad de sufragio y el voto es secreto y obligatorio a partir de los 18 años de edad.

El Poder Ejecutivo contará también con Ministros Secretarios de Estado. La ley dispondrá de cuáles serán sus funciones y cuántos serán, pero no podrán ser menos de cinco. ${ }^{74}$

Retorna la figura del Consejo de Estado, que estaba presente en la Ley de 1844 pero no en la Constitución de 1870. En el caso de la Carta de Estigarribia, se conforma por "los Ministros del Poder Ejecutivo, el Rector de la Universidad Nacional, el Arzobispo del Paraguay, un representante del comercio, dos representantes de las industrias agropecuarias, un representante de las industrias transformadoras, el Presidente del Banco de la República y

\footnotetext{
${ }^{71}$ Artículo 2. Declaraciones Generales. Constitución Nacional de la República del Paraguay. 10 de Julio de 1940.

${ }^{72}$ Artículo 34. Derechos, obligaciones y garantías. Constitución Nacional de la República del Paraguay. 10 de Julio de 1940.

${ }^{73}$ Artículos 45, 46, 47 y 49. El Poder Ejecutivo. Constitución Nacional de la República del Paraguay. 10 de Julio de 1940.

${ }^{74}$ Artículos 59, 60 y 61. Los Ministros del Poder Ejecutivo. Constitución Nacional de la República del Paraguay. 10 de Julio de 1940.
} 
dos miembros de las Instituciones Armadas, uno del Ejército y otro de la Marina, con graduación de Coronel por lo menos, en situación de retiro". ${ }^{75}$

Se extingue la figura de Vicepresidente y el Congreso pasa a ser unicameral, denominándose Cámara de Representantes, que podrá ser disuelta por el Presidente. ${ }^{76}$ Este es otro de los elementos que indican un desbalance en favor del acaparamiento de poder en el Ejecutivo. Por esta causa, Palau y Yore indicaron que esta Constitución "consagraba un presidencialismo concentrado expresado en un Poder Ejecutivo con atribuciones constitucionales extraordinarias en materia legislativa y judicial, en desmedro de la independencia y autonomía de los poderes Legislativo y Judicial, respectivamente"77 e inauguraba un cesarismo presidencial.

La Cámara de Representantes se vota directamente por el pueblo ${ }^{78}$ y se renueva íntegramente cada 5 años. Personas con cargos eclesiásticos o militares en servicio activo no pueden ser parte de la Cámara. El Poder Judicial tendrá independencia garantiza y se conformará por una Corte Suprema de tres miembros, el Tribunal de Cuentas y los demás Tribunales y Juzgados inferiores.

Al igual que en la Constitución de 1870, se presentan esbozos de fueros para proteger la acción legislativa y suspende el derecho de sufragio a las fuerzas de seguridad y del orden. ${ }^{79}$

Rescatamos aquí una curiosidad: mientras que la Constitución de 1870 indica que "la casa de Gobierno no podrá ser habitación particular del Presidente ni de ningún empleado público", ${ }^{80}$ la de 1940 establece que "el Presidente de la República residirá en la Casa de Gobierno." ${ }^{, 81}$ Una de las hipótesis para interpretar esta diferencia surge al calor de los hechos históricos recientes, a partir de la necesidad de la Carta de 1870 de desactivar todo rasgo nacionalista y de identificación del Presidente con el pueblo paraguayo y su práctica previa a la Guerra Grande, y de la necesidad de la de 1940 de recuperar la figura de Presidente fuerte e intérprete de la nación.

\footnotetext{
${ }^{75}$ Artículo 62. El Consejo de Estado. Constitución Nacional de la República del Paraguay. 10 de Julio de 1940.

76 “El Presidente de la República podrá disolver la Cámara de Representantes y remover a los Consejeros de Estado, con la obligación, en el primer caso, de convocar a elecciones dentro del plazo de dos meses" Artículo 53. El Poder Ejecutivo. Constitución Nacional de la República del Paraguay. 10 de Julio de 1940.

${ }^{77}$ Palau, Marielle y Yore, Myriam. "Presidencialismo moderado y gobierno de coalición. Emergencia y fracaso de una experiencia inédita”. Documento de Trabajo CDE, n 101, 2000: 7.

${ }^{78}$ Artículo 67. La Cámara de Representantes. Constitución Nacional de la República del Paraguay. 10 de Julio de 1940.

79 "Se suspende el sufragio del ciudadano: (...) 2) por ser soldado, cabo o sargento de tropa de línea, guardia nacional o policía bajo cualquier denominación con que sirvieren (...)"Artículo 40. Nacionalidad y Ciudadanía. Constitución Nacional de la República del Paraguay. 10 de Julio de 1940.

${ }^{80}$ Artículo 126. Adición. Constitución de la República del Paraguay. 24 de Noviembre de 1870.

${ }^{81}$ Artículo 48. El Poder Ejecutivo. Constitución Nacional de la República del Paraguay. 10 de Julio de 1940.
} 
Respecto al segundo eje, el de analizar a los colectivos sociales y a los derechos, la Carta de 1940 inaugura la expresa gratuidad de la educación primaria, ${ }^{82}$ el deber fundamental del Estado de proveer cuidado de la salud, asistencia social y educación moral, espiritual y física de la juventud ${ }^{83}$ y la obligación del Estado de vigilar los establecimientos para garantizar que los trabajadores ejerzan su actividad en un nivel compatible con la dignidad humana, quedando proscripta la explotación del hombre por el hombre, ${ }^{84}$ el odio entre los paraguayos y la lucha de clases. ${ }^{85}$ Todos los habitantes son iguales ante la ley.

Es decir, al tiempo en que concentra y acumula poder, la Constitución también incorpora una más amplia concepción de obligaciones estatales y derechos sociales, con un Estado mediador y contralor de su cumplimiento. Por ejemplo, fiscalizaba y reglamentaba "la organización, el funcionamiento y las actividades de las agrupaciones o entidades de carácter público". 86

Respecto al derecho de expresión, el artículo se mantiene pero se morigera, pues los habitantes de la República tendrán derecho a hacer públicas sus ideas por la prensa sin censura previa, pero "siempre que se refieran a asuntos de interés general" ${ }^{87}$ y estaba prohibida la prensa anónima. Además, tenían derecho a profesar libremente su culto, a aprender y a enseñar.

Incorpora los derechos civiles de la mujer, que deberán ser regulados por ley, y deberán atender a la "unidad de la familia, la igualdad de la mujer y el hombre y la diversidad de sus respectivas funciones en la sociedad". ${ }^{88}$ En esto, la Carta de 1940 es original. Asentar constitucionalmente la igualdad de la mujer y el hombre era un paso importante, en un Paraguay donde las mujeres aún no tenían derecho al voto.

Tanto la Constitución de 1870 como la de 1940 contemplaron la posibilidad de declarar estado de sitio en caso de conmoción interna o ataque exterior. En la primera, era atribución del Congreso y en la segunda, del Presidente de la República. Ambas comparten también la

\footnotetext{
82 "La educación primaria es obligatoria y gratuita". Artículo 10. Declaraciones generales. Constitución Nacional de la República del Paraguay. 10 de Julio de 1940.

${ }^{83}$ Artículo 11. Declaraciones generales. Constitución Nacional de la República del Paraguay. 10 de Julio de 1940.

${ }^{84}$ Artículo 14. Declaraciones generales. Constitución Nacional de la República del Paraguay. 10 de Julio de 1940.

${ }^{85}$ Artículo 36. Derechos, obligaciones y garantías. Constitución Nacional de la República del Paraguay. 10 de Julio de 1940.

${ }^{86}$ Artículo 32. Derechos, obligaciones y garantías. Constitución Nacional de la República del Paraguay. 10 de Julio de 1940

${ }^{87}$ Artículo 19. Derechos, obligaciones y garantías. Constitución Nacional de la República del Paraguay. 10 de Julio de 1940.

${ }_{88}$ Artículo 24. Derechos, obligaciones y garantías. Constitución Nacional de la República del Paraguay. 10 de Julio de 1940.
} 
incorporación del delito de sedición y el de traición a la patria, en el caso de la de 1940, este delito se imputa por unirse a sus enemigos o atentando contra la independencia y seguridad de la República.

La pena de muerte queda prohibida constitucionalmente, así como la confiscación de bienes.

Mantiene también de la Constitución anterior, la idea de la protección de la vida, el honor y la propiedad de todos los paraguayos.

Pasando al eje de la relación entre la Iglesia y el Estado, encontramos que, como en la Carta de 1870, la religión oficial era la Católica Apostólica Romana, "pero se toleran los demás cultos que no se opongan a la moral y al orden público. El jefe de la Iglesia Paraguaya y los Obispos deben ser ciudadanos naturales". 89 Además, encontramos nuevamente, al igual que en las dos Constituciones anteriores, que es atribución del Presidente de la República ejercer "los derechos del Patronato Nacional de la República en la presentación de Arzobispos y Obispos, a propuesta en terna del Consejo de Estado, de acuerdo con el Senado Eclesiástico o el Clero Nacional reunido; concede el pase o retiene los decretos de los Concilios, y las bulas, breves y rescriptos del Sumo Pontífice, con acuerdo del Consejo de Estado y de la Cámara de Representantes". 90

Finalmente, si abordamos el cuerpo constitucional a partir del eje de la matriz económica y productiva, esta Carta tiene artículos similares a los de la Constitución de 1870, pero también otros especialmente interesantes por su diferencia.

Entre los primeros, tenemos la obligación del Estado de afianzar relaciones de paz y de comercio con las naciones extranjeras (prestando especial atención a la colaboración y solidaridad con pueblos americanos) ${ }^{91}$ y la garantía de la propiedad privada. ${ }^{92}$

Sin embargo, entre los segundos, encontramos que esa garantía de la propiedad privada es complementada por unas frases que morigeran su liberalismo y le dan un perfil más social. De hecho, la Constitución de 1940 indica que se "garantiza la propiedad privada, cuyo contenido y límites serán fijados por la ley, atendiendo a su función social. Nadie puede ser privado de su propiedad sino en virtud de sentencia fundada en ley. La propiedad de toda clase de bienes podrá ser transformada jurídicamente mediante la expropiación por causa de

\footnotetext{
${ }^{89}$ Artículo 3. Declaraciones Generales. Constitución Nacional de la República del Paraguay. 10 de Julio de 1940.

${ }^{90}$ Artículo 51. El Poder Ejecutivo. Constitución Nacional de la República del Paraguay. 10 de Julio de 1940.

${ }^{91}$ Artículo 12. Declaraciones Generales. Constitución Nacional de la República del Paraguay. 10 de Julio de 1940.

${ }^{92}$ Artículo 21. Derechos, obligaciones y garantías. Constitución Nacional de la República del Paraguay. 10 de Julio de 1940.
} 
utilidad social definida por la ley, la que determinará a sí mismo la forma de indemnización. La ley podrá fijar la extensión máxima de tierras de que puede ser dueño un solo individuo o sociedad legalmente constituida y el excedente deberá venderse en subasta pública o expropiarse por el Estado para su distribución". 93

Es decir, incorpora el fin social como justificativo de la posesión de la propiedad; además indica que "todo hogar paraguayo debe asentarse sobre un pedazo de tierra propia". 94 Expresa también que el Estado es quien regulará la vida económica nacional. ${ }^{95}$

\section{Conclusiones}

En este trabajo hemos propuesto un recorrido sobre tres Constituciones del Paraguay que marcaron, cada una en su tiempo histórico, clivajes importantes para el país.

Para dar cuenta de ello, nos propusimos indagar sobre las dimensiones y representaciones del Estado que estas Cartas plasmaron. Entendimos estos documentos como fotografías de un proceso dinámico de influencia mutua entre el contexto y la norma. No representan en su totalidad las percepciones y los hechos acaecidos, ni tampoco expresan la recepción socio comunitaria de estas reglamentaciones. Más bien nos permiten indagar sobre la visión que los hombres de Estado tenían sobre el Estado existente y sobre el Estado posible.

En primera instancia, la Ley de Administración Pública de 1844, no está denominada como Constitución pero plantea un orden general del Estado y del Gobierno, lo que nos permitió entrever un Estado con una institucionalidad recién iniciada, con poca infraestructura pero con una fuerte impronta de dividir el poder. Plantea un Ejecutivo fuerte, que encabeza y toma decisiones, que luego son refrendadas por un Congreso que se reúne cada ciclos muy extensos de tiempo, por lo que su rol queda relegado al de acompañar la gestión del Ejecutivo.

Los derechos que reconoce son muy básicos y es sobresaliente que — tanto en ella como en las normas que respalda y que también fueron recuperadas- esgrime políticas muy focalizadas para grupos sociales específicos, generalmente en un estado de vulnerabilidad y precariedad manifiesta y significativa. Es un Estado con poco desarrollo social, mucho más atento al peligro de la Guerra y al potencial riesgo de las relaciones exteriores y regionales.

La relación con la Iglesia es pujante y se va afianzando, sobre todo después del gobierno de Gaspar Rodríguez de Francia, quien la había desfinanciado y socavado sus influencias y

\footnotetext{
${ }^{93}$ Artículo 21. Derechos, obligaciones y garantías. Constitución Nacional de la República del Paraguay. 10 de Julio de 1940.

${ }^{94}$ Artículo 22. Derechos, obligaciones y garantías. Constitución Nacional de la República del Paraguay. 10 de Julio de 1940.

${ }_{95}$ Artículo 15. Declaraciones Generales. Constitución Nacional de la República del Paraguay. 10 de Julio de 1940.
} 
poder. El Estado es Católico y prohíbe otros cultos explícitamente, a pesar de la ocasión de firmar acuerdos específicos de migración.

Respecto a la matriz económica, es interesante la incorporación de la moneda acuñada nacionalmente, los intentos de comerciar con territorios vecinos, y la reorganización de aduanas e impuestos.

La Constitución de 1870 tiene otro perfil, mucho menos Ejecutivo, en el que el Congreso de dos Cámaras adquiere atribuciones que le son quitadas al Presidente. Esta Carta tiene una base liberal y quita la pena de muerte que tenía la anterior, priorizando al habitante, su virtud y su propiedad.

Si bien existen los tres poderes, como en la Ley de 1844, en esta se encuentran en una sintonía de mayor equilibrio y autonomía. El Presidente ya no será, como en los tiempos de López, elegido por el Congreso, sino por una junta electoral conformada por representación territorial.

La Constitución reconoce más derechos relacionados a la libertad de las personas, a la libre expresión y a la libertad de culto y de prácticas que no contradigan al bienestar nacional. Respeta que se profesen otras religiones, aunque prioriza la religión Católica Apostólica Romana y tanto el presidente como el vicepresidente deben ser de este credo.

La propiedad es inviolable, como la libertad, la vida y el honor. El Estado debe garantizar que cada persona pueda trabajar y comerciar, y que se desarrollen acuerdos de paz y comercio con naciones extranjeras.

Por su parte, la Constitución de 1940 (cuya nomenclatura también es disputada) vuelve a depositar en el Presidente una cantidad de poder mayor, al tiempo de que reduce el Congreso de dos Cámaras a una sola, que además podía ser desintegrada por el Presidente. Esto horadó la independencia y autonomía de los diferentes órganos del Estado.

Mantiene de la Constitución de 1870 el estado de sitio y el delito de sedición, ambos peligrosos al considerar los derechos de los habitantes. Respecto a esto último, señalamos una incorporación novedosa: los derechos civiles de las mujeres y el derecho a la tierra, así como la obligación de Estado de velar por la dignidad humana de los trabajadores en el ejercicio de su oficio. Esto demuestra una paradojal acumulación de poder en el Presidente, con un control riguroso de actividades y decisiones, pero, al mismo tiempo, la incorporación del requisito de utilidad social para justificar la propiedad privada y el reconocimiento del derecho de toda familia paraguaya a poseer un pedazo de tierra sobre el que vivir. En este sentido, sería de interés para estudios posteriores, indagar sobre los parecidos y continuidades entre esta forma 
de entender el rol del Estado y el colectivo social, y el acuerdo corporativo más tradicional de los fascismos.

Vuelve a una versión más restringida del derecho de expresión y si bien también oficializa al catolicismo, se propone tolerar los demás cultos.

Como podemos ver, los modelos constitucionales plantean Estados híbridos, que dan cuenta del contexto regional de ideas pero que también incorporan elementos propios que hacen a los clivajes políticos del contexto de emergencia de estas Constituciones.

Por ejemplo, al revisar la trayectoria histórica tanto de Paraguay como de la región, no impacta como extraña la concentración de poder y la dinámica propuesta entre Congreso y Presidente dentro de la Ley de 1844. Asimismo, si entendemos que la Constitución de 1870 fue aprobada bajo una ocupación de las fuerzas aliadas, tampoco sorprende la similitud con la Constitución Argentina y el refuerzo puesto en disminuir la personalización del poder, tanto por la experiencia argentina como la experiencia paraguaya y la interpretación que se hacía en Argentina de las causas que habían llevado al Paraguay a entrar en la guerra. También, analizando la alternancia y concatenación caótica de Presidentes, los golpes de Estado entre correligionarios y no correligionarios, se encuentra el argumento para que Estigarribia plantee un acuerdo constitucional cesarista que garantizaría el orden a fuerza de centralizarlo en torno al Presidente.

Los cambios más importantes se encuentran entre la Constitución de 1844 y la de 1870, pues la de 1870 tuvo como intención desandar los caminos estatales previos a la Guerra e inaugurar un nuevo tiempo normativo. Las continuidades se hallan, de todas formas, entre las tres, y eso también se debe a un contexto de ideas imperantes, que eran las categorías disponibles para pensar el Estado, el Gobierno y la Nación. 